Research article

\title{
Genetic microheterogeneity and phenotypic variation of Helicobacter pylori arginase in clinical isolates Justin G Hovey ${ }^{1}$, Emily L Watson ${ }^{2}$, Melanie L Langford ${ }^{3}$, Ellen Hildebrandt ${ }^{4}$, Sangeetha Bathala ${ }^{1}$, Jeffrey R Bolland ${ }^{5}$, Domenico Spadafora ${ }^{1}$, George L Mendz 6 and David J McGee*4
}

Address: ${ }^{1}$ Department of Microbiology and Immunology, University of South Alabama College of Medicine, Mobile, AL, USA, ${ }^{2}$ Department of Medicine, Creighton University School of Medicine, Omaha, NE, USA, ${ }^{3}$ Department of Biological Sciences, University of Nebraska-Lincoln, Lincoln, NE, USA, ${ }^{4}$ Department of Microbiology and Immunology, Louisiana State University Health Sciences Center, Shreveport, LA, USA, ${ }^{5}$ Department of Microbiology, University of Alabama at Birmingham, Birmingham, AL, USA and ${ }^{6}$ School of Medical Sciences, University of New South Wales, Sydney, Australia

Email: Justin G Hovey - justinhovey@gmail.com; Emily L Watson - emilywatson@creighton.edu; Melanie L Langford - mlang@bigred.unl.edu; Ellen Hildebrandt - ehilde@lsuhsc.edu; Sangeetha Bathala - sangeethabathala@hotmail.com; Jeffrey R Bolland - jbolland@uab.edu;

Domenico Spadafora -dspadafora@jaguar1.usouthal.edu; George L Mendz - g.mendz@unsw.edu.au; David J McGee* - dmcgee@lsuhsc.edu

* Corresponding author

Published: 4 April 2007

BMC Microbiology 2007, 7:26 doi:10.1186/1471-2180-7-26
Received: 22 November 2006

Accepted: 4 April 2007

This article is available from: http://www.biomedcentral.com/I47/-2/80/7/26

(C) 2007 Hovey et al; licensee BioMed Central Ltd.

This is an Open Access article distributed under the terms of the Creative Commons Attribution License (http://creativecommons.org/licenses/by/2.0), which permits unrestricted use, distribution, and reproduction in any medium, provided the original work is properly cited.

\begin{abstract}
Background: Clinical isolates of the gastric pathogen Helicobacter pylori display a high level of genetic macro- and microheterogeneity, featuring a panmictic, rather than clonal structure. The ability of $H$. pylori to survive the stomach acid is due, in part, to the arginase-urease enzyme system. Arginase (RocF) hydrolyzes L-arginine to L-ornithine and urea, and urease hydrolyzes urea to carbon dioxide and ammonium, which can neutralize acid.

Results: The degree of variation in arginase was explored at the DNA sequence, enzyme activity and protein expression levels. To this end, arginase activity was measured from 73 minimallypassaged clinical isolates and six laboratory-adapted strains of $H$. pylori. The rocF gene from $2 \mathrm{I}$ of the strains was cloned into genetically stable $E$. coli and the enzyme activities measured. Arginase activity was found to substantially vary (>100-fold) in both different $H$. pylori strains and in the $E$. coli model. Western blot analysis revealed a positive correlation between activity and amount of protein expressed in most $H$. pylori strains. Several $H$. pylori strains featured altered arginase activity upon in vitro passage. Pairwise alignments of the $2 \mathrm{l}$ rocF genes plus strain $\mathrm{J99}$ revealed extensive microheterogeneity in the promoter region and 3' end of the rocF coding region. Amino acid S232, which was 1232 in the arginase-negative clinical strain A2, was critical for arginase activity.
\end{abstract}

Conclusion: These studies demonstrated that $H$. pylori arginase exhibits extensive genotypic and phenotypic variation which may be used to understand mechanisms of microheterogeneity in $H$. pylori. 


\section{Background}

Helicobacter pylori, a Gram negative bacterium, is a highly host-adapted gastric pathogen that has been implicated in a wide spectrum of diseases ranging from gastritis to adenocarcinoma [1-5]. Although this bacterium colonizes the gastric mucosa of billions of people, only $20 \%$ of the infected people become symptomatic. The disparities of symptoms from one person to another are indicative of a pathogen with significant genetic diversity. Two major types of diversity have been described in $H$. pylori clinical isolates: i) macrohetereogeneity, in which large chromosomal regions vary from strain to strain, and ii) microheterogeneity, in which individual genes feature sequence diversity. Examples of macroheterogeneity include the presence or absence of the cag pathogenicity island, insertion sequences, and a hypervariable region containing about half of the strain-specific genes, called the plasticity zone [6-14]. Furthermore, 22\% of the organism's genes are dispensable in one or more strains, leading to a core of only about 1280 genes [13]. Macroheterogeneity can be assessed by restriction fragment length polymorphisms, multilocus enzyme electrophoresis, and microarrays.

Examples of microheterogeneity include extensive sequence variation of the vacA, cagA, babA, hopQ, iceA genes and other genes [9,15-20]. For example, the vacA gene encoding the vacuolating cytotoxin (VacA) exhibits a remarkable degree of genotypic and phenotypic variation [9,21-23]. The vacuolating activity of VacA varies approximately 30-fold across different isolates due to the presence of at least five different vacA alleles [24]. Two families of the vacA alleles, type $\mathrm{m} 1$ and type $\mathrm{m} 2$, are only about $70 \%$ identical [25]. In addition, there is also evidence that mixed strain infections can occur in a single patient [26], and that a single strain can change in vivo over time $[16,27,28]$. The extraordinary diversity of this pathogen may explain why the acquired immune response cannot clear the infection or prevent reinfection by a heterologous strain. The genetic variation among the bacterium's virulence factors may relate to the diverse disease manifestations in patients, although this is not well understood.

On the other hand, the urease structural proteins, UreA and UreB, are very well conserved across heterologous strains of $H$. pylori (97-100\% amino acid identity, based on BlastP analysis of GenBank sequences). These proteins constitute a nickel-requiring, highly abundant metalloenzyme that is central to the pathogenesis of the bacterium [29]. Urease hydrolyzes urea to carbon dioxide and ammonia, the latter of which neutralizes gastric acid [30]. Local neutralization of gastric acid helps $H$. pylori to safely traverse the gastric mucosal layer and colonize the gastric epithelium [31]. Indeed, urease mutants are unable to colonize and establish a lasting infection in nude mice and gnotobiotic piglets [32-34]. Considering that functional urease is absolutely essential for virulence, numerous random mutations in the functional core of the urease gene could be detrimental, thus explaining why ure $A$ and ureB are highly conserved in heterologous strains. Without stability in these two structural genes, this species would be ineffective as a pathogen.

The source of urea for $H$. pylori urease can either be through host- or bacterial-derived arginase. H. pylori contains the rocF gene encoding arginase, which catalyzes the hydrolysis of L-arginine to L-ornithine and urea [35-37]. H. pylori is deficient in the enzymes for synthesizing arginine de novo and is therefore dependent on host arginine to help it maintain nitrogen balance [36-38]. Arginase consumes arginine, thereby removing this essential amino acid away from other cellular processes if the enzyme activity is too high. The role of arginase in $H$. pylori pathogenesis is beginning to be unraveled. Arginase allows the bacterium to evade host immune response by competing with macrophage inducible nitric oxide synthase (iNOS) for L-arginine [39]. H. pylori arginase also down-regulates expression of CD $3 \varsigma$ on T-cells, preventing their proliferation via consumption of arginine from the extracellular milieu [40]. Moreover, arginase produces endogenous urea that can be hydrolyzed by urease to produce ammonium that contributes to acid resistance [35]. Thus, arginase is involved in helping $H$. pylori evade both the innate (acid, NO) and adaptive (T cells) immune systems. Arginase clearly plays a role in these pathogenic processes, but surprisingly the rocF gene encoding arginase is not essential for the establishment of infection [35], suggesting that in vivo the enzyme plays a role downstream of the initial colonization step, perhaps modulating disease severity.

The importance of specific mutations in the phenotypic variation of this species are largely unknown. The evolution of specific genes and proteins in this pathogen are of paramount importance as the field strives to understand the role of specific genes in virulence. In a previous study involving laboratory-adapted strains, some variation in arginase activity was found among three strains [35]. However, it was not determined whether this variation occurred from spontaneous mutation from passaging the strains repeatedly in the laboratory or from natural diversity existing among $H$. pylori strains. To determine arginase variability, phenotypic and genotypic analyses of $r o c F$ in 73 minimally-passaged clinical isolates and six laboratory-adapted strains was investigated. While most previous studies on microheterogeneity focused on only a small portion of a gene, we studied the entire arginase coding region plus upstream region. This study demonstrates that extensive microheterogeneity exists in the rocF gene, with phenotypic manifestations, and provides evi- 
dence that this gene may serve as a model to study microheterogeneity in $\mathrm{H}$. pylori.

\section{Results \\ Variation of arginase activity in clinical isolates of $\mathbf{H}$. pylori}

Previously, a modest 1.6-fold variability in arginase activity was reported in three laboratory-adapted strains of $H$. pylori [35]. In this study, the potential variability of arginase activity was examined in much more detail using 73 minimally-passaged clinical isolates of $H$. pylori from patients with different disease manifestations and from different geographical locations (Table S1, see additional file 1). The clinical isolates have been passaged fewer than five times on laboratory media and therefore their arginase activity would be closer to that found in vivo. Six laboratory-adapted strains (G27, J99, 26695, 43504, SS1, and $3401)$ were used as controls. Arginase activities of extracts from $H$. pylori strains revealed dramatic variations exceeding 100-fold among the isolates (Fig. 1A; Table S1 in additional file 1). Three different categories could be arbitrarily assigned to the isolates: high activity (> $5000 \mathrm{U}$; $\mathrm{n}=2$ isolates), intermediate activity (1000 U to $5000 \mathrm{U} ; \mathrm{n}$ $=38$ isolates), and low activity ( $<1000 \mathrm{U} ; \mathrm{n}=39$ isolates). For nearly all strains, arginase activity remained constant within experimental error for each strain following three consecutive passages. However, repeated passaging of several strains over the period of seven to nine days, changed their arginase activity, with some increasing (J75, SS1) and some decreasing $(26695, \mathrm{~J} 104)$ (see below; data not shown). No clear correlation could be made between arginase activity and disease status of the patient, although the number of isolates available for certain diseases types (e. g., cancer, duodenal ulcer, duodenitis) was too low to determine significant correlations.

To determine whether an alternative growth medium also resulted in variable arginase activity, $H$. pylori strains were grown in Ham's F-12 broth and corresponding extracts assayed for arginase activity. Arginase activity also varies in broth, depending on the strain, but there was a strong correlation (correlation coefficient $=0.9$ ) between arginase activity of a particular strain in broth versus agar (Fig. 1B). In other words, strains with low arginase activity on agar also had low arginase activity in broth.

Although we previously determined that $r o c F$ mutants of H. pylori have wild type levels of urease activity [35], we sought to determine whether arginase and urease activities correlated, using a larger number of strains. Twelve clinical isolates of $H$. pylori were measured for urease activity and compared with arginase activity. Notably, there was more than 25 -fold variation in urease activity among clinical isolates examined (Fig. S1A, see additional file 2). Variation in urease activity in fresh clinical isolates was 3- 10-fold in previous studies using less sensitive urease activity methods $[41,42]$. There was no correlation whatsoever between urease and arginase activities (correlation coefficient $=0.04$ ) (Fig. S1B, see additional file 2). For example, some strains had low arginase but high urease activties while other strains had low activities of both enzymes.

\section{E. coli expressing the arginase gene from different $\mathbf{H}$. pylori clinical isolates displays variable activity}

The variation in arginase enzyme activity observed in $H$. pylori could be due to sequence differences in the arginase protein itself or in other loci which may affect the enzyme. To eliminate the genetic variability of other $H$. pylori loci as a compounding factor, arginase activity was assessed in the genetically stable E. coli model developed previously [43]. The arginase gene with its native promoter from 20 of the strains used in this study, representing low, intermediate and high arginase activities, was cloned into pBluescript and arginase activity measured in transformed E. coli. (Although the rocF gene from strain G27 was cloned and sequenced, arginase activity from E. coli carrying this clone was not directly compared to the others, because the rocF gene was in a different plasmid and strain of E. coli from the rest of the clones. However, the G27 rocF did confer arginase activity to E. coli Top $10[14,200 \mathrm{U}$ versus $700 \mathrm{U}$ in insert-free vector control strain pCR2.1). Remarkably, arginase activity depended on the particular arginase gene cloned into $E$. coli, with a greater than $100-$ fold magnitude of variation (Fig. S2, see additional file 3). Surprisingly, there was absolutely no correlation $\left(\mathrm{r}^{2}=\right.$ 0.0749 ) between the arginase activity from $E$. coli containing a particular rocF gene and the arginase activity of the $H$. pylori strain from which the rocF gene was cloned (data not shown). For example, H. pylori strain A5 has almost no detectable arginase activity, yet the rocF gene from this strain conferred arginase activity to E. coli. H. pylori strain A4 has one of the highest arginase activities among all the clinical isolates (4431 U), yet its arginase gene conferred among the lowest arginase activities to E. coli. Thus, the data also raise the possibility that there are strain-specific H. pylori loci that modulate arginase activity. We hesitate to make other firm conclusions due to plasmid copy number effects potentially having an influence on the arginase activity levels observed.

\section{Evidence for strain-specific regulation of $\mathrm{H}$. pylori arginase activity}

Disruption of the rocF gene results in abolishment of arginase activity $[35,44]$. A new chromosomal complementation system for $H$. pylori that targets the hp0203-204 intergenic region demonstrated that the arginase mutant of strain 26695 could be complemented for arginase activity [44]. 


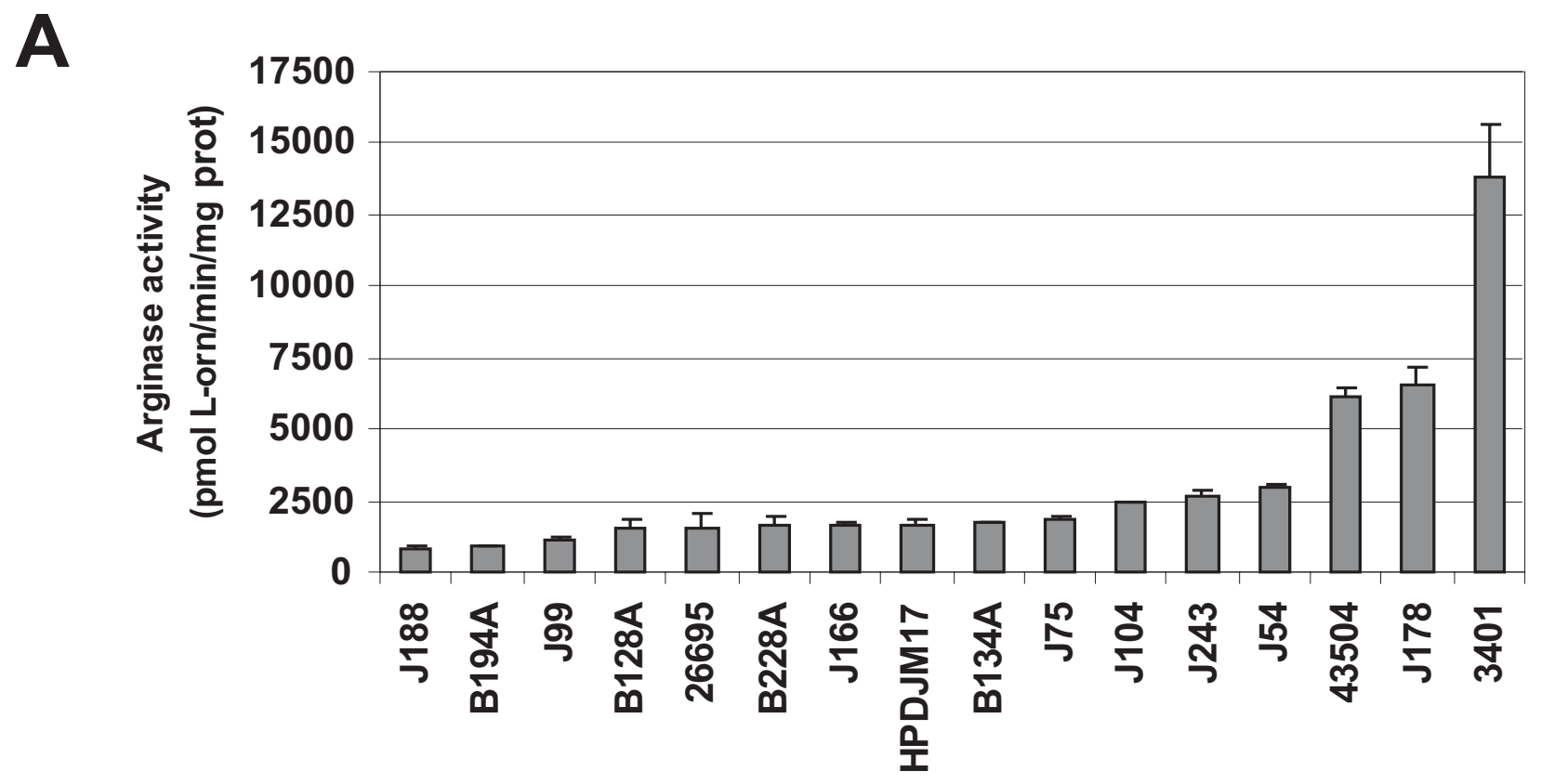

B

Arginase activity, pmol L-orn/min/mg

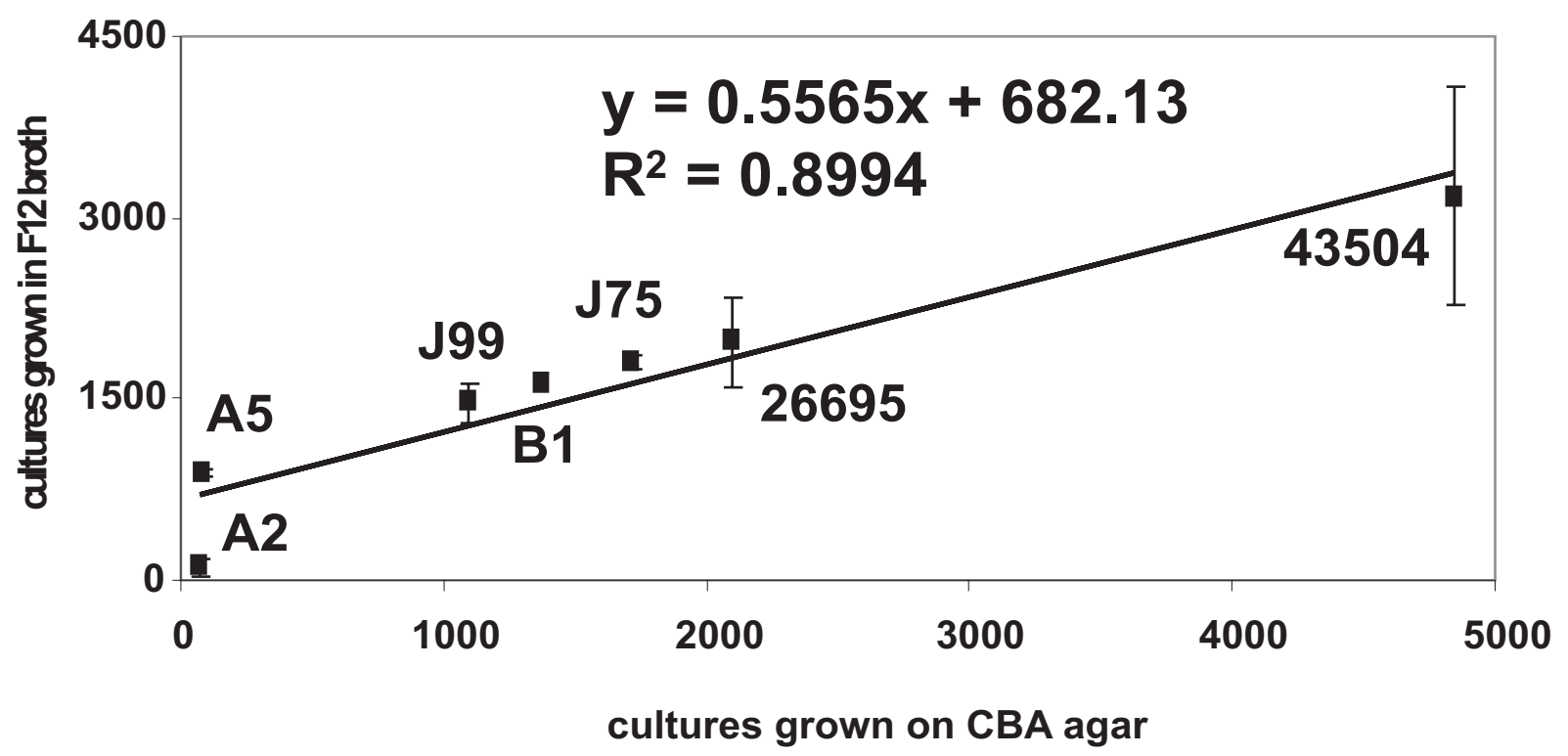

Figure I

Arginase activity variation in $\boldsymbol{H}$. pylori clinical isolates. Ornithine concentration was measured at $5 \mathrm{I} 5 \mathrm{~nm}$ spectrophotometerically by the appearance of an orange color originating from the reaction of ornithine with acidified ninhydrin. A. Arginase activity of extracts from 16 US $H$. pylori strains, II of which are minimally-passaged clinical $H$. pylori isolates. Strains were grown on Campylobacter blood agar plates for $48 \mathrm{~h}$. The graphs show the average arginase activity (pmol L-Orn/min/mg protein) \pm standard deviation of one experiment representative of at least three. A complete list of strains and average arginase activities is given in Table SI (see Additional file I). The variation from experiment to experiment is about I0-15\%. B. Comparison of arginase activity of $H$. pylori grown in broth versus grown on agar. H. pylori strains were grown in Ham's F- 12 broth for 16-18 h or on Campylobacter blood agar plates for $48 \mathrm{~h}$ as described in Materials and Methods. The data suggest a strong correlation between the arginase activity from $H$. pylori grown in broth versus that on agar. 
Three plasmids, pMLB001, pMLB002, and pMLB003 carry the wild type rocF genes from $H$. pylori strains 43504, SS1 and J63, respectively. These suicide plasmids were transformed into the rocF mutant of 26695 and confirmed to yield 26695 rocF-MLB001, -MLB002, and -MLB003 [44]. The arginase activity of these three complemented strains was compared to that of the corresponding wild type $H$. pylori strain from which the rocF gene was derived. When the rocF genes from strains 43504 or SS1 were used to complement the 26695 rocF mutant, arginase activity was restored to levels similar to that of the corresponding wild-type 43504 or SS1 strains (Fig. 2). In contrast, when the rocF gene from strain J63 was used to complement the 26695 rocF mutant, arginase activity was about ten times higher than that of the corresponding wild-type J63 strain (Fig. 2). This finding raises the intriguing possibility that there is strain-dependent regulation of arginase.

Additional evidence for strain-dependent arginase activity was revealed from strains SS1, B5 and B1, which all have identical rocF coding regions and upstream regions, yet have different arginase activities (8100, 1900, $1400 \mathrm{U}$, respectively) (Table S1 in additional file 1).

\section{Evidence that H. pylori prefers low to moderate arginase activity}

The arginase activity data from clinical isolates revealed that most strains possess intermediate or low arginase activities, while only a few strains have high activity, with only one strain above 10,000 U (strain 3401). If H. pylori did not control arginase activity, then a strain with two functional chromosomal copies of the arginase gene should have an enzyme activity significantly higher than the wild type strain carrying only a single arginase gene. To investigate this plasmid pMLB004, which confers arginase activity to an arginase negative strain, was transformed into the high arginase activity strain, SS1, to yield two chromosomal copies of wild-type rocF (each with its native promoter), designated SS1 MLB004 [44]. As an isogenic control, the same construct devoid of the arginase gene (pIR203C04) was transformed into SS1 to yield SS1 203 C04 [44]. Rather than the predicted 100\% increase, strain SS1 MLB004 had only about 25\% more arginase activity over that of the isogenic control SS1 203C04 strain (Fig. 3). This suggests that $H$. pylori has mechanisms to prevent arginase activity from becoming too high.

\section{Western Blot analysis of arginase in clinical isolates of $\mathbf{H}$. pylori}

Western blot analysis with RocF antiserum showed that extracts from $H$. pylori strains with high arginase activity (e. g., 3401, A4) had relatively higher amounts of arginase protein (Fig. 4, only a subset shown), than most strains with lower arginase activity (e. g., J188, A2). There were occasional exceptions; strain J63, for example, had low arginase activity, but high amounts of arginase protein (Fig. 4). It was difficult to detect arginase protein in some of the lowest arginase activity strains, such as strains A2, A5, A6, A7 (Fig. 4). Two strains whose arginase activity changed upon laboratory passage (J104 increased while SS1 decreased), likewise showed corresponding changes in the amount of arginase protein (Fig. 4). The arginase protein size by SDS-PAGE was found to vary slightly among the minimally-passaged clinical isolates; this size variation did not correlate with arginase activity (e. $g$., 3401 vs. B128A) (Fig. 4). Despite slight size variations, all roc $F$ genes were predicted to encode a 322 amino acid protein. The size variation was not considered significant enough to study further.

\section{Nucleotide, amino acid and phylogenetic analyses of rocF/ RocF}

To understand better the arginase nucleotide sequence variations, strains representing low, intermediate and high arginase activity were selected for further analysis. PCR amplification was performed on 21 different arginase genes, each giving a $1.1 \mathrm{~kb}$ fragment, which was cloned and sequenced. Pairwise alignments of the nucleotide sequences of 22 strains (including the J99 rocF sequence already in the database, GenBank accession \#AE001565; strain AG1 excluded) revealed that the rocF coding sequences $(\sim 1.0 \mathrm{~kb})$ were $92.9 \%$ to $100 \%$ identical to that of strain 26695 (data not shown). Within the region encoding the arginase putative cobalt-binding site, DAHAD (Fig. 5A), two corresponding nucleotide changes were observed: GAC to GAT (strains SS1, J75, B1, B7, and J166) and GCG to GCT (strain AG1). In both cases, the mutations were silent, leading to no changes in the amino acid sequence. Alignments also revealed a hypervariable region in the upstream sequence proximal to the ATG start codon (Fig. 5B). The region between nucleotides -37 to +3 ranged from only $67 \%$ to $100 \%$ identity with strain 26695 (Fig. 5C). Ten different sites showed mutations; insertions and deletions also occurred in this hypervariable region (Fig. 5B and 5C). Interestingly, some of the mutations, insertions and deletions, occurred near or in the predicted Shine-Dalgarno sequence (ribosome-binding site) (26695 rocF SD sequence: AGGAGTTATA) (Fig. 5A and $5 \mathrm{~B})$. Intriguingly, the arginase upstream region from the recently sequenced $H$. pylori strain AG1 [45] had no homology with that of any of the arginase upstream regions studied here (data not shown). Instead, the arginase upstream region of strain AG1 showed striking resemblance (92\% nucleotide identity) to that of the arginase upstream region of $H$. acinonychis [46] (data not shown). In contrast, the arginase upstream sequence from the remaining $22 \mathrm{H}$. pylori strains studied here did not bear any homology to any region in the $H$. acinonychis genome (data not shown). 


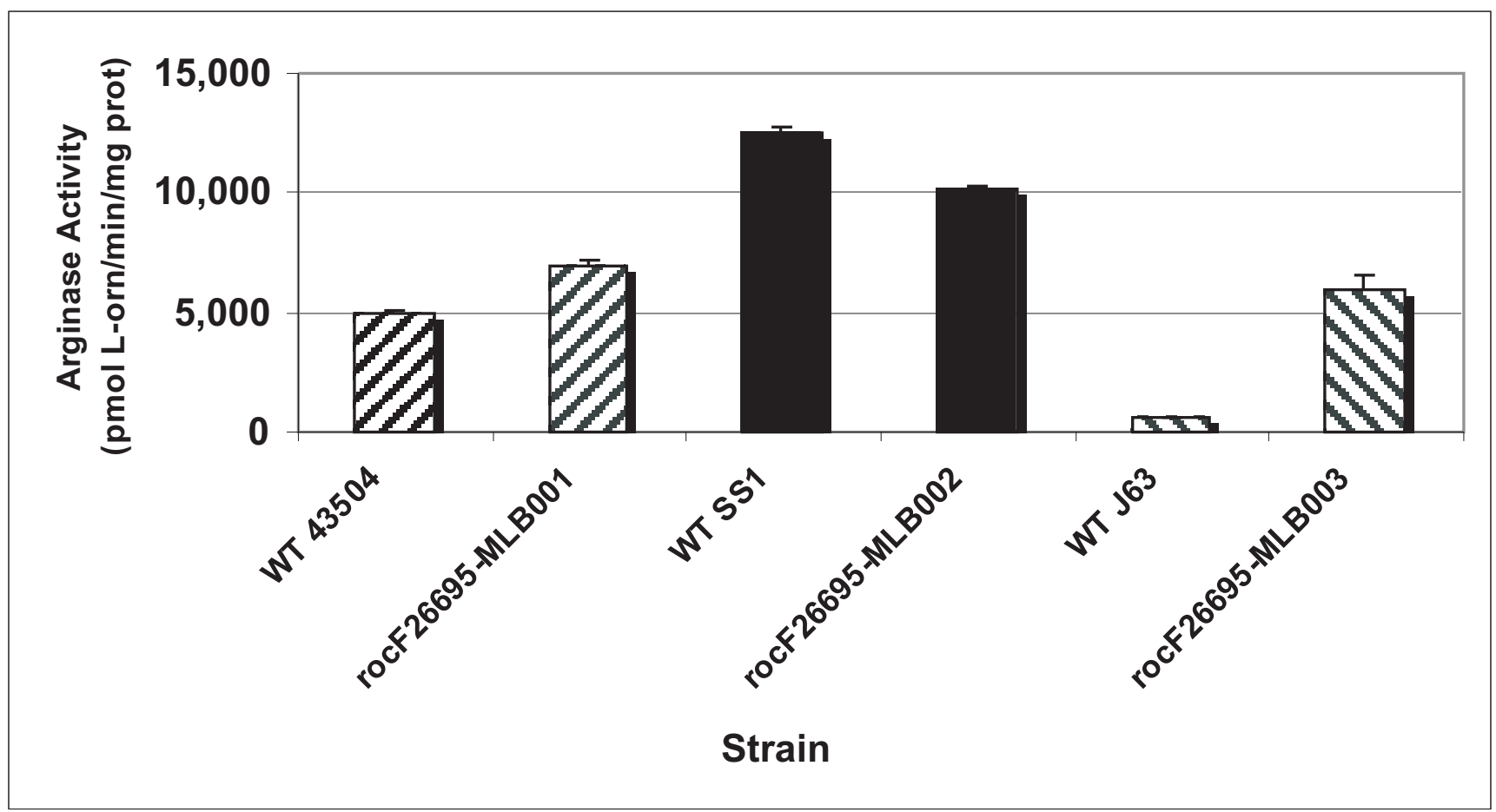

Figure 2

Strain-specific regulation of $\boldsymbol{H}$. pylori arginase activity. Comparison of arginase activities of a native $H$. pylori strain and a rocF mutant strain of 26695 complemented with the corresponding rocF gene (coding region plus native rocF promoter). Strain rocF-26695-MLB00I is a rocF mutant of strain 26695 in which the wild type rocF gene from strain 43504 has been complemented. The MLB002 strain carried wild type rocF from strain SSI and the MLB003 strain carried wild type rocF from strain J63.

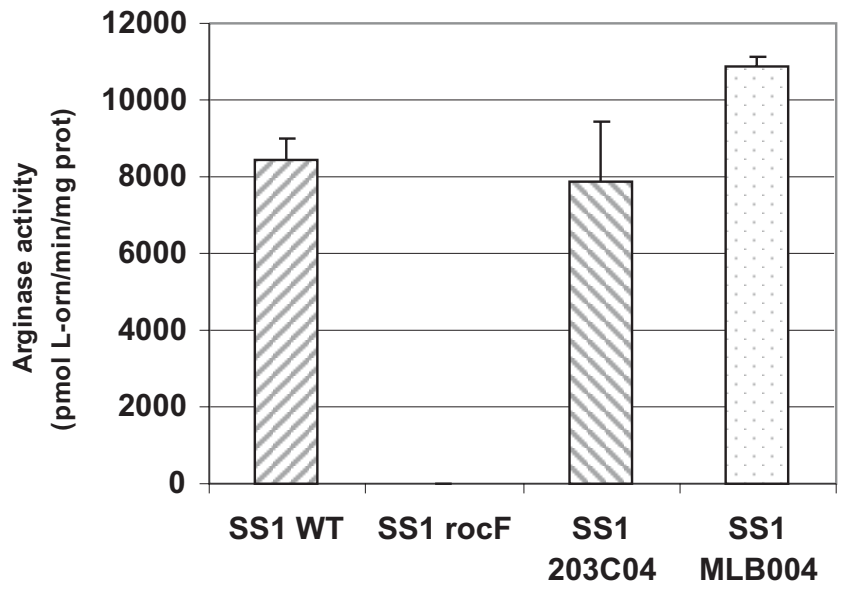

Figure 3

H. pylori prevents arginase activity from becoming too elevated. Wild type $H$. pylori strain SSI was transformed with the rocF mutation (rocF), a vector control inserted into the intergenic hp0203-0204 site (203C04), or with the intergenic plasmid carrying the wild type rocF coding region and native promoter (MLB004).
Pairwise alignments of the translated RocF coding regions showed that they were $92 \%$ to $100 \%$ identical, with most variability located near the carboxy terminus (Fig. 5A). There were 42 amino acid residues out of 322 (13\%) that were not $100 \%$ conserved across all the isolates. Of these 42,28 of the variable residues are found in the last 100 amino acids, with nine of these variable sites being in the final 16 amino acids at the C-terminal end. Three strains, SS1, B5, and B1, were 100\% identical at the nucleotide and amino acid levels. Strains HPDJM17 and J188 had five amino acid differences. All $H$. pylori RocF proteins were predicted to have 322 amino acids.

A phylogenetic tree of the arginase proteins from $23 \mathrm{H}$. pylori strains revealed four clades, with $16,4,2$, or 1 strain(s) in the clades (Fig. 5D). A phylogenetic tree of the nucleotide sequences of the arginase upstream region from $22 \mathrm{H}$. pylori strains (strain AG1 excluded) showed three major clades containing one, fifteen and six strains, respectively (Fig. 5E). The two phylogenetic trees (Fig. 5D, $5 \mathrm{E})$ showed little congruence with each other. For example, the RocF protein from strains 43504 and A4 were within the same clade, but the corresponding rocF 

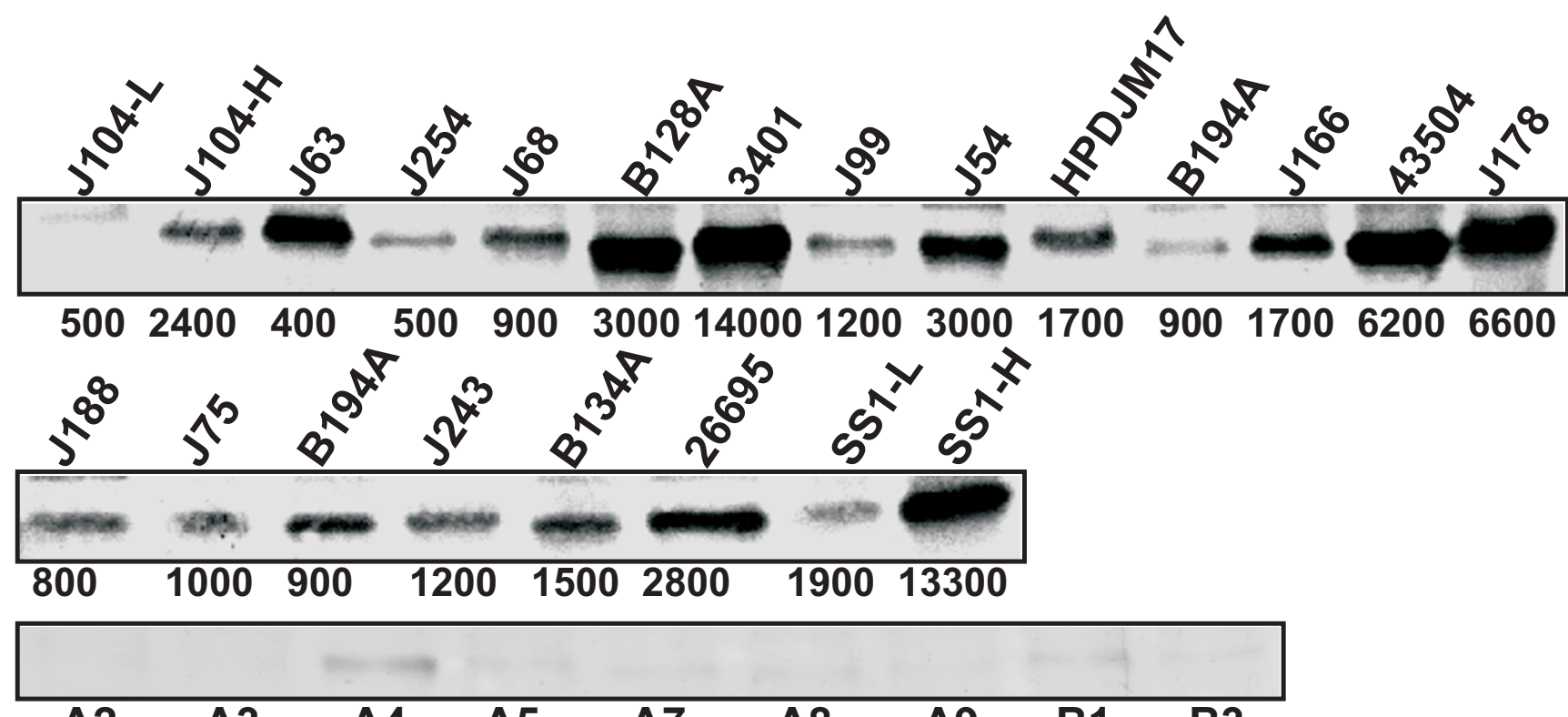

$\begin{array}{lllllllll}\text { A2 } & \text { A3 } & \text { A4 } & \text { A5 } & \text { A7 } & \text { A8 } & \text { A9 } & \text { B1 } & \text { B3 }\end{array}$

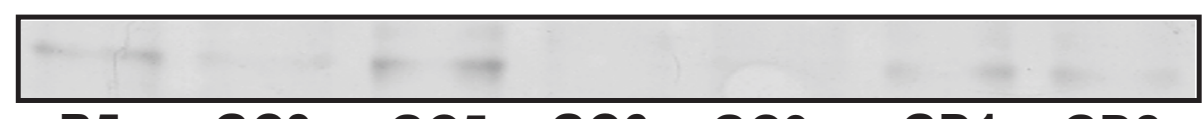

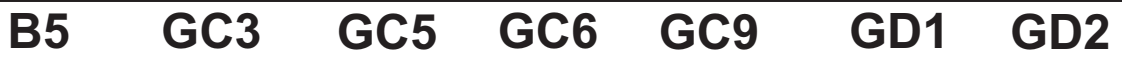
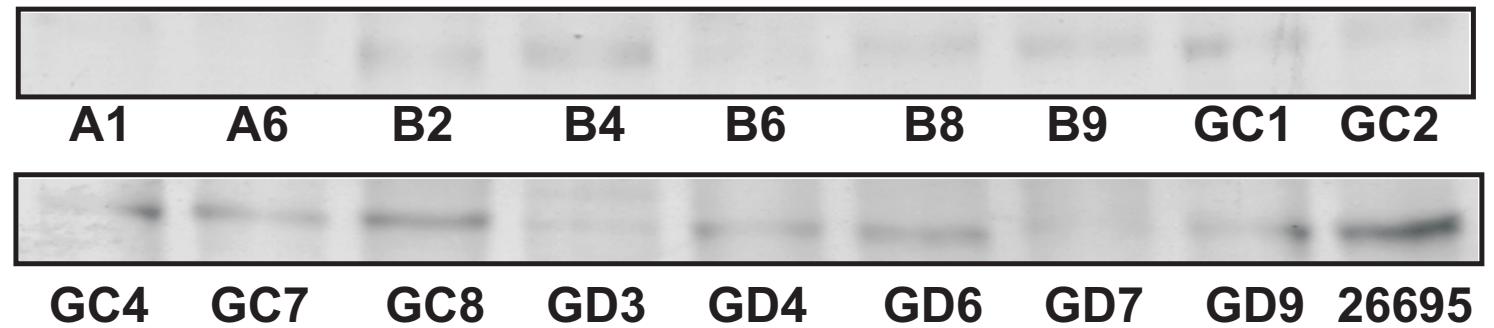

Figure 4

Anti-RocF Western on minimally-passaged wild type $\boldsymbol{H}$. pylori. Proteins were separated by SDS-PAGE using a I2\% resolving gel and $10 \mu \mathrm{g}$ of protein loaded per lane and analyzed by anti-RocF antibodies. Only a subset of strains is shown. JI04L, low arginase activity strain minimally passaged; JI04-H, high arginase activity strain passaged for seven to nine days; SSI-L, low arginase activity strain passaged for seven to nine days; SSI-H, high arginase activity strain minimally-passaged. Numbers below the top two blots represent the arginase specific activity (rounded to nearest 100; pmol L-ornithine/min/mg protein \pm standard deviation) of the extract used for the blot.

upstream regions were in different clades. Two strains showing $100 \%$ identity in the arginase upstream region were strains G27 and B7, two of the highest arginase activity strains (3900 $\mathrm{U}$ and $4800 \mathrm{U}$, respectively) (Fig. 5C, $5 \mathrm{E})$. These two strains did not have identical coding regions, showing 96\% identity at the amino acid level. Three other strains were $100 \%$ identical in the upstream region: B5, SS1, and B1 (Fig. 5C, D). These three strains were also $100 \%$ identical at the amino acid level (Fig. 5D), yet had different levels of arginase activity (Fig. 5C). This provided additional evidence that a strain-specific locus other than rocF plays a role in some of the variability observed. No clear correlation could be made between phylogenetic placement on either of the trees (Fig. 5D, E) and the level of arginase activity (Table S1 in additional file 1).

\section{Serine $\mathbf{2 3 2}$ in RocF is required for arginase activity}

No information is available regarding the amino acids in H. pylori RocF that are responsible for catalytic activity. The clinical isolate A2 had barely detectable arginase activity (68 U) we designate as arginase null (Fig. 6A). The arginase gene and protein sequences were directly compared to that of a strain with much higher arginase activ- 
A
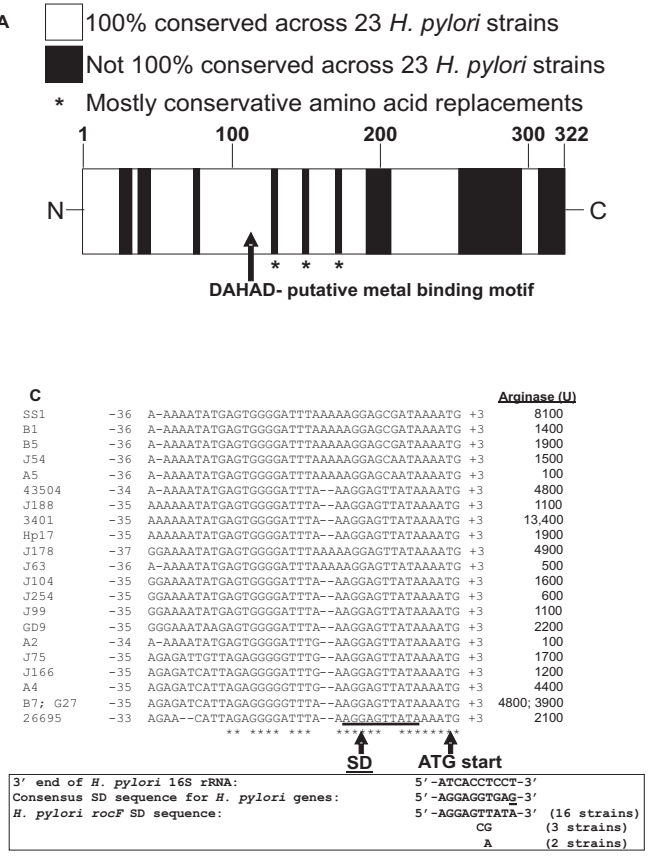

E

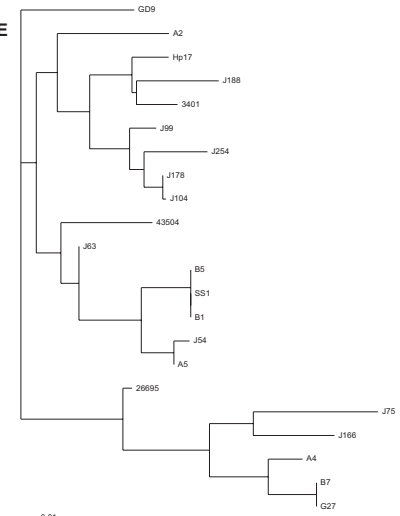

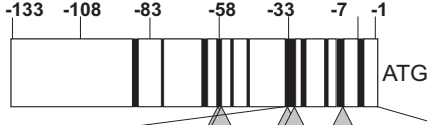
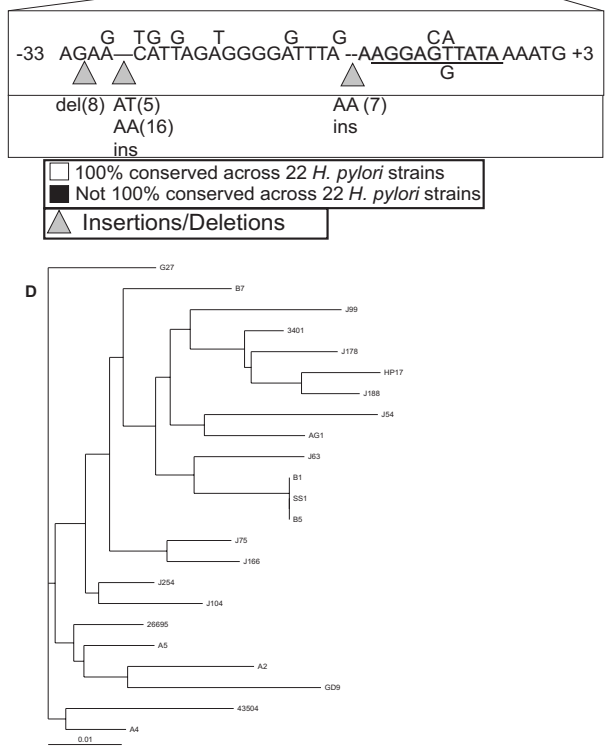

Figure 5

Microheterogeneity in arginase sequences from clinical isolates of $\boldsymbol{H}$. pylori. The arginase coding region $(\sim 1.0 \mathrm{~kb})$ plus $\sim 130$ bp of the upstream region encompassing the promoter and 18 bp downstream were amplified by PCR using Pfx and cloned into pBluescript. The constructs were sequenced using T3 and T7-I primers (see Materials and Methods). A. Summary of microheterogeneity in the arginase coding region in $\mathrm{H}$. pylori. Multi-sequence pairwise alignments were conducted with the rocF coding region using ClustalW. The alignment was converted to a graphical representation to show regions that are $100 \%$ conserved (white) and regions that vary (black). B. Hypervariablity in the $\sim 133$ bp rocF upstream region including the arginase promoter sequence preceding the ATG start codon. Multi-sequence pairwise alignments of the $\sim 133 \mathrm{bp}$ rocF upstream region from $H$. pylori strains were conducted using ClustalW. The alignments were converted to a graphical representation to show regions that are $100 \%$ conserved (white) and regions that vary (black). The alignments revealed a hypervariable region proximal to the ATG start codon. Numbering based on that of $H$. pylori strain 26695 . Underlined is the Shine-Dalgarno (SD) sequence. Numbers in parentheses correspond to the number of strains featuring the insertion (ins) or deletion (del). Strain AGI was omitted from this analysis because its arginase upstream region was completely different from the other 22 strains. C. Hypervariability in the $\sim 35$ bp upstream of the arginase ATG translation start codon in $21 \mathrm{H}$. pylori strains. Some of the sequence hypervariability occurred in the predicted SD region (underlined). The consensus sequence for the $3^{\prime}$ end of the I6S rRNA for $H$. pylori is shown, as well as the consensus SD sequence for other $H$. pylori genes. Arginase activity is shown on the right hand side in units rounded to the nearest 100. Asterisks indicate nucleotides conserved in all strains. D. Phylogram of RocF protein sequence from $23 \mathrm{H}$. pylori strains. ClustalX and Treeview were used to construct the tree. E. Phylogram of the rocF upstream region from $22 \mathrm{H}$. pylori strains. ClustalX and Treeview were used to construct the tree. Strain AGI was omitted from this analysis because its arginase upstream region was completely different from the other 22 strains. 
ity, 26695. Alignment of the $\sim 70$ bp rocF upstream sequences of both strains revealed nine differences (Fig. $6 \mathrm{~B})$, but none of the changes in strain A2 could be correlated to an arginase null phenotype, since these changes were found in other arginase upstream regions in strains with detectable arginase activity. An additional $60 \mathrm{bp}$ further upstream of these two strains was next analyzed and shown to be $100 \%$ identical (data not shown). The involvement of these upstream sequences in affecting the arginase null phenotype of strain A2 could not be completely ruled out. Next, the RocF amino acid sequences of strains A2 and 26695 were aligned, revealing 11 amino acid differences (Fig. 6C). All but three of these amino acid differences were found in arginase proteins from other strains of $H$. pylori that had detectable arginase activity, suggesting the other eight residues were not involved in the original arginase null phenotype of strain A2. The roles of the remaining three amino acids (strain 26695: I174, S232, D257; strain A2: M174, I232, N257) in arginase activity were investigated in RocF from strain 26695 using site-directed mutagenesis. Each of these residues was mutated from the wild type 26695 sequence to the $\mathrm{A} 2$ sequence in $\mathrm{PQE3} 3$-rocF [43]: isoleucine 174 was mutated to methionine (I174M), serine 232 was mutated to isoleucine (S232I), and aspartate 257 was mutated to asparagine (D257N). Arginase activity was measured from crude extracts prepared from E. coli harboring these plasmid derivatives. Plasmid pQE30 served as the negative control and the original wild type pQE30-rocF (from strain 26695) [43] served as the positive control. Arginase activity data indicated that the I174M and D257N mutations had no major effect on the activity of the enzyme. Strikingly, arginase activity in extracts from the strain carrying the S232I mutation strain was abolished, with no activity above the negative control strain carrying pQE30 (Fig. 6D). Western blot analysis using anti-RocF antiserum revealed that the amount of expressed arginase protein in the S232I mutant was similar to that of wild type 26695 RocF expressed from pQE30-rocF (Fig. 6E), indicating that the S232I mutated form of the protein was properly expressed. However, a more pronounced degradation of RocF (RocF frag in Fig. 6E) compared with the wild type RocF was noted.

\section{Discussion}

In this study the phenotypic and genotypic heterogeneity of arginase in 73 clinical isolates and six laboratoryadapted strains of $H$. pylori was investigated. Phenotypically, arginase activity varied more than 100 -fold in both H. pylori (Fig. 1) and the E. coli model (Fig. S2 in additional file 3). Nearly all of the H. pylori strains featured intermediate or low arginase activities (77 of 79 strains). Of the five strains with the highest arginase activity, four were laboratory strains that have been passaged heavily. Notably, even the highest arginase activity strains (3401 and SS1 laboratory strains) have specific activities more than 10-fold lower than those measured for other bacterial and eukaryotic arginases (McGee, unpublished data). Arginine is a critical amino acid for several cellular processes, such as protein synthesis, and $H$. pylori absolutely requires arginine for growth [47-49]. The bacterium would rapidly hydrolyze the arginine if it had a high specific activity arginase, potentially depleting intracellular pools and starving itself of this essential amino acid. The few high arginase activity $H$. pylori strains may have compensatory mechanisms to overcome potential arginine starvation from the higher level of arginine hydrolysis. Two possible mechanisms are that the high arginase activity strains might have a higher affinity arginine transporter that would allow higher intracellular accumulation of arginine. Alternatively, the high arginase activity strains could have decreased arginine decarboxylase activity, another arginine-consuming enzyme that could also cause arginine depletion in $H$. pylori.

H. pylori is a heterogeneous species $[23,50]$ that features diversity at many levels. For example, there are many contingency genes that undergo phase variation through DNA slipped-strand mispairing of repeats, such as LPS biosynthesis genes, and genes encoding outer-membrane proteins [51]. As another example of diversity, adhesion of $H$. pylori to fucosylated Lewis B antigens on the surface of the gastric epithelium appears to be dependent on variability of the $b a b A$ gene. This gene shows much conservation in the $5^{\prime}$ and 3 ' regions but large variability in its midregions [52]. The cagA gene, encoded by the cag pathogenicity island, exhibits nucleotide sequences that are $92.8 \%$ conserved, with much diversity at the 3 ' end where an EPIYA amino acid repeat element is encoded $[53,54]$. RocF also features diversity in its C-terminal region, although there are no repeat elements. RocF appears to more divergent than urease subunits $A$ and $B$, but less divergent than CagA or VacA. Since rocF participates in various aspects of H. pylori pathogenesis $[39,40]$ and the gene displays remarkable heterogeneity shown in this study, it is possible that rocF heterogeneity may correlate with specific aspects of the pathogenesis of the bacterium, such as inhibition of nitric oxide production and T-cell proliferation. The data obtained do not provide evidence for a correlation between arginase activity and urease activity or between arginase activity and the disease status of the patient, although more isolates would need to be studied since there were few isolates available for certain disease categories. Moreover, a greater geographic distribution of strains also would be necessary.

The data support the hypothesis that some H. pylori strains may have strain-specific arginase gene regulation. For example, strain A5 has minimal to no detectable arginase activity in the native $H$. pylori strain, but significant activity 
$\mathbf{A}$

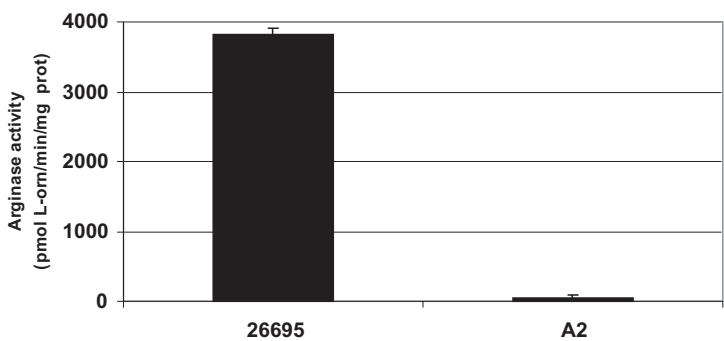

B

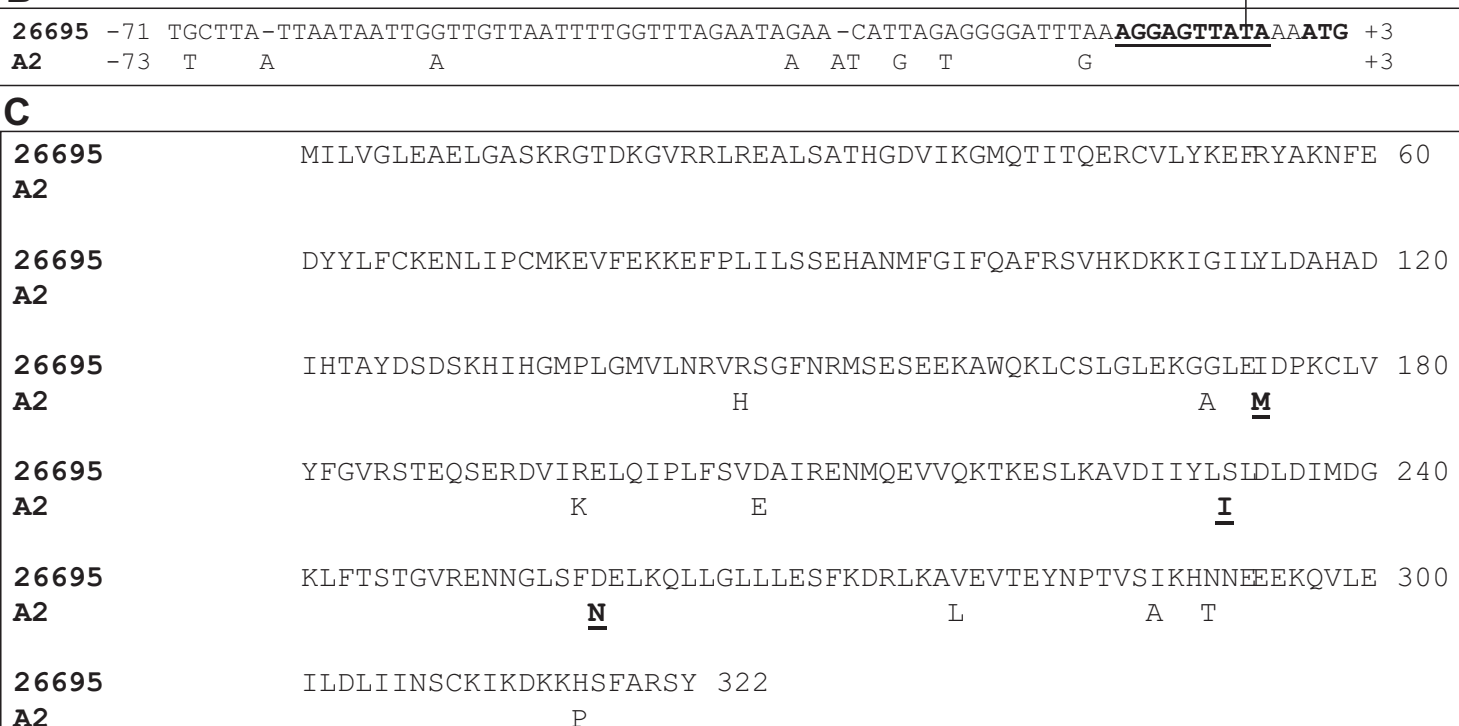

A2
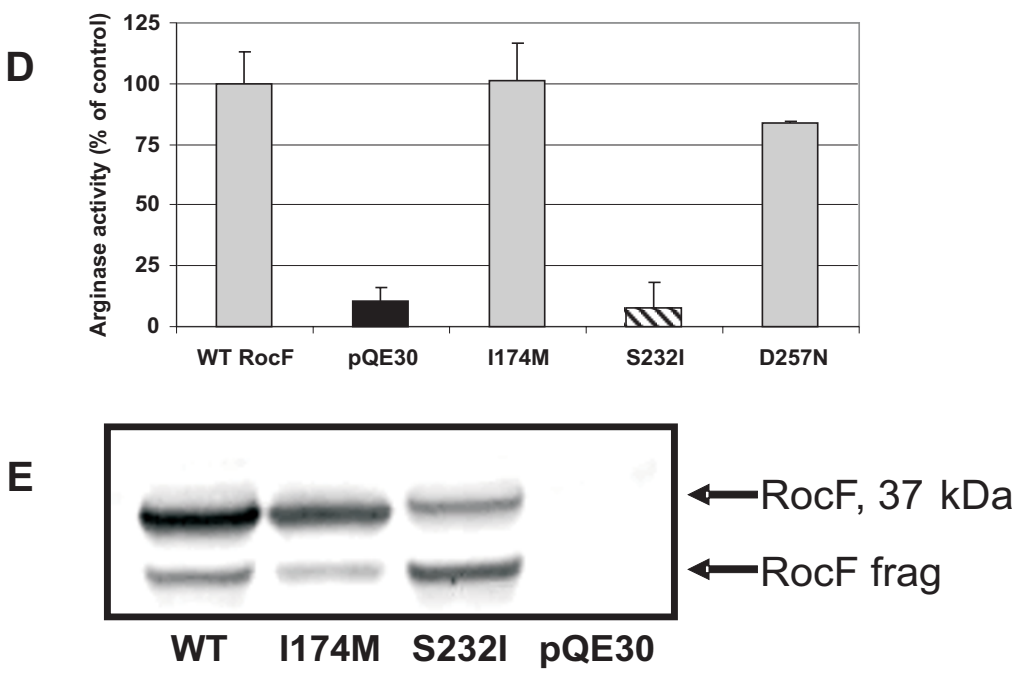

\section{Figure 6}

Molecular basis of the arginase null phenotype of $\boldsymbol{H}$. pylori clinical isolate A2. A. Arginase activity of $H$. pylori strain 26695 and clinical isolate A2. B. Variation in the arginase upstream regions of $H$. pylori strains 26695 and A2. Nine nucleotide differences were noted between these two sequences. C. Variations in the arginase amino acid sequences between $H$. pylori strains 26695 and A2. Eleven amino acid differences are highlighted (3I I/322 identity [ $96 \%$ identity]; 3 I6/322 similar [ $97 \%$ similar]. Three amino acid differences (underlined) were found only in strain A2: II 74M, S232I, and D257N. D. Arginase activity of E. coli transformed with PQE30-rocF (rocF from strain 26695) and of strains transformed with site-directed mutants of II74M, S232I, and D257N. E. Anti-RocF Western blot analysis of extracts of $E$. coli transformed with different plasmids including sitedirected mutants of RocF. RocF frag indicates degradation product from RocF. 
was detected in E. coli transformed with the A5 rocF gene, suggesting that $H$. pylori strain A5 has an arginase repressor. Such a repressor may be inoperative, inefficient, or absent in high arginase activity strains such as 3401. Additionally, evidence for potential strain-specific arginase regulation was observed in $H$. pylori directly. Specifically, arginase activity of $H$. pylori strain J63 is low, but when the rocF gene from this strain was used to complement a rocF mutant of strain 26695 in single copy on the chromosome, a surprisingly elevated arginase phenotype was observed, suggesting that strain 26695 has an activator protein absent in strain J63 or strain J63 has a repressor protein absent from strain 26695. A possible molecular basis for this potential variation may be due to the hypervariablity in the upstream region, which displays variation in the Shine-Dalgarno (SD) region, as well as variation in the region shown by DNAse footprinting experiments to be bound by the ArsR regulator [55]. Mutations in the upstream region could either affect transcriptional expression, or translational control through changes in strength of the SD sequence. Evidence in the literature also supports the rocF gene being regulated at the transcriptional level by acid [56] and by the two-component system ArsS/ R (Hp0165/0166) [55]. Strain-specific transcriptional and translation regulation mechanisms are not mutually exclusive.

Besides the hypothesized strain-specific arginase transcriptional and translation regulation, evidence was obtained that variations in the rocF sequence themselves play a key role in arginase activity, using the genetically stable E. coli model. E. coli is arginase negative, but when the $H$. pylori arginase genes were cloned into E. coli, variable arginase activity occurs. Since enzyme activity varied dramatically with the particular arginase gene cloned into E. coli, variations in the rocF sequence would also be responsible for at least some of the arginase phenotypic variation. H. pylori strain-specific regulators that could affect arginase transcription in native $H$. pylori strains most likely would be absent in the E. coli model. Pairwise alignments of rocF nucleotide sequences revealed significant microheterogeneity in the 3 ' end of the coding regions, and translation of these regions showed that RocF varies in the carboxy terminus. Variations near the C-terminus could possibly affect the folding of the arginase active site, thereby accounting for some of the arginase activity variation.

Evidence for the direct involvement of the rocF coding region in arginase activity variation was obtained from site-directed mutagenesis results. Specifically, mutation of serine 232 to isoleucine in RocF from strain 26695 completely abolished arginase activity, helping to explain why H. pylori strain A2, which has isoleucine in position 232 in its native arginase, showed barely detectable arginase activity. Thus, amino acid 232 appears to play a crucial role in arginase activity. Notably, the rocF gene from strain A2 conferred the lowest arginase activity to E. coli among the 20 rocF genes examined (Fig. S2 in Additional file 3). The possibility that other amino acid residues, or nucleotides in the rocF upstream region also play a role in the arginase null phenotype of strain A2 cannot be ruled out. Future experiments will endeavor to elucidate the mechanism of why serine 232 is so critical for arginase activity, as there is no prior precedent for a serine being required for arginase activity.

Evidence was also obtained that arginase activity could vary upon in vitro passage of some strains; the mechanism of this variation remains undefined. That the phylogenetic trees of the arginase promoter and the arginase protein bore little resemblance to each other suggested that each region is evolving via independent selective pressures. The greater nucleotide variability among arginase upstream regions compared with the coding regions suggests that the former has a higher mutation rate and more tolerance to nucleotide changes during selection of those mutations.

\section{Conclusion}

It was established that arginase varies genotypically and phenotypically among minimally-passaged clinical $H$. pylori isolates. Future work could center on understanding in greater detail the molecular basis of arginase activity variation, and identifying strain-specific arginase regulators. This would lead to improved understanding of the mechanisms by which $H$. pylori genes undergo changes leading to microheterogeneity as the organism strives to survive in its seemingly inhospitable gastric niche.

\section{Methods \\ Bacterial strains, growth conditions, and plasmids}

All H. pylori strains were cultured on Campylobacter agar containing $10 \%$ defibrinated sheep blood (CBA) at $37^{\circ} \mathrm{C}$ for $48 \mathrm{~h}$ in a microaerobic environment $\left(\begin{array}{lll}5 \% & \mathrm{O}_{2} /\end{array}\right.$ $10 \% \mathrm{CO}_{2} / 85 \% \mathrm{~N}_{2}$ ) in humidified air. For broth conditions, $H$. pylori strains were inoculated at $4 \times 10^{6} \mathrm{CFU} / \mathrm{ml}$ as determined by ATP assay [48] into $25 \mathrm{ml} \mathrm{Ham}$ 's F-12 [49] with $2 \%$ fetal bovine serum and grown without aeration for $16-18 \mathrm{~h}$ in a microaerobic environment. The minimally-passaged clinical isolates were obtained from Richard Peek (Vanderbilt University, 15 isolates), George Mendz (University of Sydney, Australia, 40 isolates), Barbara Schneider (Louisiana State University, New Orleans, 17 Colombian isolates) and one previously described clinical isolate (HPDJM17) [57] (Table S1 in additional file 1). The laboratory-adapted strains were SS1, 43504, 26695, J99, G27 and 3401. All isolates were passaged fewer than five times from the frozen stock, except in cases 
in which the effects of in vitro passage on arginase activity were studied.

E. coli strain DH5 $\alpha$ was used for cloning and transformation procedures and XL1-Blue MRF' was utilized for the pQE30-based plasmids used in this study. E. coli was grown on Luria (L) agar and $\mathrm{L}$ broth plus appropriate antibiotics (ampicillin, $100 \mu \mathrm{g} / \mathrm{ml}$; tetracycline, $15 \mu \mathrm{g} / \mathrm{ml}$ ) at $37^{\circ} \mathrm{C}$. Plasmid pBS [pBluescript II SK (+); Stratagene] was used for cloning rocF genes.

Preparation of arginase or urease-containing cell extracts $H$. pylori and E. coli were harvested in $0.9 \% \mathrm{NaCl}$ and sonicated in an ice-bath (two pulses at 25\% intensity, $30 \mathrm{sec}$ each with $30 \mathrm{sec}$ rest between pulses). Following centrifugation $\left(12,000 \times g\right.$, two $\left.\min , 4^{\circ} \mathrm{C}\right)$, the supernatants were retained on ice until measurement of arginase activity. Protein concentrations were determined by the bicinchoninic acid method using bovine serum albumin as a standard (Pierce, Rockford, IL).

\section{Arginase activity assay}

Arginase activity was measured using a colorimetric arginase assay developed and validated previously [43]. The extracts were heat-activated $\left(50^{\circ} \mathrm{C}, 30 \mathrm{~min}\right)$ in the presence of $5 \mathrm{mM}$ cobaltous chloride to provide the enzyme with its required metal cofactor, followed by incubation in the presence of $15 \mathrm{mM}$ MES-10 $\mathrm{mM}$ arginine buffer (pH 6.0) for $1 \mathrm{~h}$ at $37^{\circ} \mathrm{C}$. The ornithine produced was detected spectrophotometrically at $515 \mathrm{~nm}$ in the presence of acidified ninhydrin $(4 \mathrm{mg} / \mathrm{ml})$. Data are presented as mean arginase specific activity ( 1 Unit $(U)=1$ pmol Lornithine produced per minute per milligram protein).

\section{Urease activity assay}

Urease activities were measured using the phenolhypochlorite method as described previously [58].

\section{SDS-PAGE and Western blot analysis of arginase extracts}

Bacterial proteins were separated by sodium dodecyl sulfate-polyacrylamide gel electrophoresis (SDS-PAGE) using a $12 \%$ resolving gel and $10 \mu \mathrm{g}$ of protein loaded per lane. These electrophoresed proteins were then transferred to methanol-treated polyvinylidene difluoride membrane using the Trans-blot cell transfer system (BioRad). The blots were subsequently blocked in $5 \%(\mathrm{w} / \mathrm{v})$ nonfat dry milk in Tris-buffered saline containing $0.5 \%$ (v/v) Tween-20 (TBST-1), and incubated with the primary RocF antiserum $(1: 2,500)$ for $2 \mathrm{~h}[43]$. After three washes with TBS containing $0.05 \%(\mathrm{v} / \mathrm{v}$ ) Tween-20 (TBST-2), goat anti-rabbit IgG-conjugated alkaline phosphatase (Sigma Immunochemical Co.; $1: 5,000$ to $1: 7,500)$ was added and incubated for $90 \mathrm{~min}$. Following a triple wash with TBST2 , the blot was equilibrated with glycine buffer $(100 \mathrm{mM}$ glycine, $1 \mathrm{mM} \mathrm{ZnCl}_{2}, 0.05 \%(\mathrm{w} / \mathrm{v})$ sodium azide, and 1
$\mathrm{mM} \mathrm{MgCl}_{2}, \mathrm{pH}$ 10.4). To develop the blot, 3-indoxyl phosphate $(10 \mu \mathrm{g} / \mathrm{ml})$ and nitroblue tetrazolium $(100 \mu \mathrm{g} /$ $\mathrm{ml}$ ) in glycine buffer were used.

\section{Molecular biology techniques}

Plasmid DNA was extracted by column chromatography (Qiagen) or by alkaline lysis [59]. Restriction endonuclease and ligation reactions were conducted according to the manufacturer's guidelines (Promega). PCR reactions $(50 \mu \mathrm{l})$ contained 50-250 ng of DNA, 1-2 $\mathrm{mM} \mathrm{MgSO}_{4}$ $0.20-0.25 \mathrm{mM}$ dNTPs, $200 \mathrm{pmol}$ of each primer, $2.5 \mathrm{U}$ of Pfx polymerase (Invitrogen) and $10 \times$ Pfx polymerase buffer (Invitrogen). E. coli was transformed by the heat shock $\mathrm{CaCl}_{2}$ method.

\section{Cloning of rocF into $p B S$}

The rocF gene from clinical isolates and laboratoryadapted strains was PCR-amplified using the primers RocF-F27 (gcctgcagTCAAAAACTTGAATGGTTTTACTCTTT; PstI site underlined; non-rocF sequence in lower case) and RocF-R28 (ggatcgatGTTTGGTTTGAAAAGCGATCA; ClaI site underlined; non-rocF sequence in lower case). The conditions for PCR amplification were set at $94^{\circ} \mathrm{C}$ for 5 minutes; $\left[94^{\circ} \mathrm{C}, 15\right.$ seconds; $52^{\circ} \mathrm{C}$, 30 seconds; $68^{\circ} \mathrm{C}, 1$ minute 30 seconds] $\times 30$; $68^{\circ} \mathrm{C}$ for 5 minutes; $4^{\circ} \mathrm{C}$ overnight. After amplification, the PCR products (1118 bp) were analyzed by gel electrophoresis and purified via Qiaquick DNA extraction (Qiagen), and then cloned into pBS predigested with EcoRV. Following an overnight ligation, E. coli DH5 $\alpha$ was transformed by the calcium chloride method and the colonies screened via the blue-white method using X-gal [59].

\section{Cloning of rocF from strain $\mathbf{G 2 7}$ into pBS}

The rocF gene was PCR-amplified as described above and cloned directly into pCR2.1 in E. coli strain Top10 by electroporation, according to manufacturer's guidelines (Invitrogen).

\section{Sequencing of rocF genes}

Plasmid DNA from white transformants was purified by Qiagen column chromatography and was digested with ClaI and PstI restriction endonucleases to confirm presence of the insert. The rocF inserts were sequenced using T3 (forward primer; AATTAACCCTCACTAAAGGG) and T7-1 (reverse primer; GTAATACGACTCACTATAGGGC) by the Sanger dideoxynucleotide method at Iowa State University DNA Sequencing and Synthesis Facility. The sequence data have been deposited into the GenBank database as accession numbers EF126010 to EF126032.

\section{Sequence and phylogenetic analysis}

The sequences of the rocF gene of clinical isolates and laboratory-adapted strains were analyzed by BLAST searches, sequence alignments, and sequence translations at the 
National Center for Biotechnology Information website [60]. Amino acid analyses of arginase proteins were carried out at the Expert Protein Analysis System Server [61]. Multi-sequence analysis comparisons were conducted using CLUSTALW version $1.82[62,63]$ and files saved as *.aln, followed by importation into ClustalX [64]. The neighbor-joining bootstrap algorithm with 111 generator seeds and 1000 trials was used to create a Phylip output file. The Phylip output file was used to draw the phylogenetic tree in TreeView version 1.6.6 [65,66].

\section{Site-directed mutagenesis of $\mathbf{2 6 6 9 5}$ rocF}

Plasmid pQE30-rocF, harboring the wild-type rocF gene from $H$. pylori strain 26695, was mutated using the Quik Change kit following the manufacturer's instructions (Stratagene, La Jolla, CA). The primer sequences were as follows: 1) I174M: DM141-RocFI174M-F1 5'GGAGGGTTAGAAATGGATCCTAAATGTTTG3'; DM142-RocFI174M-R1

5'CAAACATTTAGGATCCATTTCTAACCCTCC3' (Introduces extra BamHI site, underlined); 2) S232I: DM143RocFS232I-F1

5'GATATTATTTATCTCATTTTGGATTTGGAC3'; DM144RocFS232I-R1 5'GTCCAAATCCAAAATGAGATAAATAATATC3';

\section{3) D257N: DM266-D257NrocF-F1} 5'GGCTGAGTTTTAATGAACTCAAGCAATTACTGG3'; DM267-D257NrocF-R1 5'CCAGTAATTGCTTGAGTTCATTAAAACTCAGCC3';

4) RocF-F6: gcggatccATGATTTTAGTAGGATTAGAAGCAGAG; BamHI site underlined; non-rocF sequence in lower case); 5) RocF-R8: gcctgcagAGTAACTCCTTGCAAAAGA GTGCTTC; PstI site underlined; non-rocF sequence in lower case). All constructs were confirmed by sequence analyses.

\section{Authors' contributions}

JGH co-designed the study, drafted the manuscript, collected data on arginase activity in some $H$. pylori strains, conducted some of the arginase Western blots, and PCR amplified, cloned and sequenced the rocF gene from about half the strains; ELW conducted some of the arginase Western blots, conducted some of the arginase assays from E. coli and H. pylori strains, and PCR amplified, cloned and sequenced some of the arginase genes; MLL conducted the experiments on strain-specific arginase regulation and overexpression and provided detailed editorial comments on the manuscript; $\mathrm{EFH}$ conducted arginase activity in F-12 broth cultures; SB conducted arginase assays on $H$. pylori strains; JRB conducted some of the arginase assays from E. coli and H. pylori; DS conducted the site-directed mutagenesis of arginase and conducted the related arginase and Western blot assays; GLM assisted with writing the manuscript, critically analyzed the data and provided numerous strains for the study; DJM conceived of and designed the study, directed the execution of the study, conducted the phylogenetic analyses, conducted the urease assays, prepared some of the figures, and edited later drafts of the manuscript. All authors read and approved the final manuscript.

\section{Additional material}

\section{Additional file 1}

Table S1. Characteristics and arginase activity of $\mathrm{H}$. pylori strains used in this study.

Click here for file

[http://www.biomedcentral.com/content/supplementary/14712180-7-26-S1.doc]

\section{Additional file 2}

Fig. S1. Urease activity of clinical isolates of $\mathrm{H}$. pylori. H. pylori strains were grown on Campylobacter blood agar for 48 h and measured for urease activity using the phenol hypochlorite method. Urease activity is shown as nmol ammonium per min per $m g$ protein \pm standard deviation. A. Urease activity of 12 clinical isolates. B. Comparison of urease and arginase activities from the same 12 clinical isolates. There was no correlation between the arginase activity and the urease activity of the strains.

Click here for file

[http://www.biomedcentral.com/content/supplementary/1471-

2180-7-26-S2.pdf]

\section{Additional file 3}

Fig. S2. Variation of arginase activity in E. coli. Arginase activity was assessed in the genetically stable background of $\mathrm{E}$. coli in order to eliminate the genetic variability of other $\mathrm{H}$. pylori loci as a compounding factor. Arginase activity in $\mathrm{E}$. coli containing rocF genes from different $\mathrm{H}$. pylori strains. The rocF genes from $20 \mathrm{H}$. pylori strains were cloned into pBS and the arginase activities from plasmid-bearing $\mathrm{E}$. coli clones were measured. The graph shows the average arginase activity (pmol L-Orn/ $\mathrm{min} / \mathrm{mg}$ protein) \pm standard deviation of one experiment representative of three. Plasmid names include the $\mathrm{H}$. pylori strain name from which the rocF gene was derived. For example, pJH254-1 carries rocF from $\mathrm{H}$. pylori strain J254, pJH17 carries rocF from strain HPDJM17, and procFB1 carries rocF from strain B1.

Click here for file

[http://www.biomedcentral.com/content/supplementary/14712180-7-26-S3.pdf]

\section{Acknowledgements}

The University of South Alabama Medical Student Summer Research Program for support of JGH is appreciated. Thanks are given to R. Peek, N. Salama and B. Schneider for providing some of the $H$. pylori strains used in the study. We thank Harry Mobley for assistance with the urease measurements. The technical support of Katherine Horton is greatly appreciated. This work was supported by Public Health Service grant CA I0193I (to DJM) from the National Institutes of Health, and the Australian Research Council (to GLM). 


\section{References}

I. Blaser MJ: Gastric Campylobacter-like organisms, gastritis, and peptic ulcer disease. Gastroenterology 1987, 93(2):371-383.

2. Blaser MJ: Helicobacter pylori and the pathogenesis of gastroduodenal inflammation. Journal of Infectious Diseases 1990, I 6 I (4):626-633

3. Marshall BJ, McGechie DB, Rogers PA, Glancy RJ: Pyloric Campylobacter infection and gastroduodenal disease. Medical Journal of Australia 1985, I 42(8):439-444.

4. Nomura A, Stemmermann GN, Chyou PH, Kato I, Perez-Perez GI, Blaser MJ: Helicobacter pylori infection and gastric carcinoma among Japanese Americans in Hawaii.[see comment]. New England Journal of Medicine I99|, 325(16): I I32-II36.

5. Parsonnet J, Friedman GD, Vandersteen DP, Chang Y, Vogelman JH, Orentreich N, Sibley RK: Helicobacter pylori infection and the risk of gastric carcinoma. N Engl ] Med I99|, 325( | 6): | | 27- I | 3 |.

6. Akopyanz N, Bukanov NO, Westblom TU, Berg DE: PCR-based RFLP analysis of DNA sequence diversity in the gastric pathogen Helicobacter pylori. Nucleic Acids Research 1992, 20(23):6221-6225.

7. Akopyanz N, Bukanov NO, Westblom TU, Kresovich S, Berg DE DNA diversity among clinical isolates of Helicobacter pylor detected by PCR-based RAPD fingerprinting. Nucleic Acids Research 1992, 20(19):5 |37-5142.

8. Alm RA, Ling LS, Moir DT, King BL, Brown ED, Doig PC, Smith DR Noonan B, Guild BC, dejonge BL, Carmel G, Tummino PJ, Caruso A Uria-Nickelsen M, Mills DM, Ives C, Gibson R, Merberg D, Mills SD, Jiang Q, Taylor DE, Vovis GF, Trust TJ: Genomic-sequence comparison of two unrelated isolates of the human gastric pathogen Helicobacter pylori. Nature 1999, 397(67| 5): I76-| 80.

9. Atherton JC, Cao P, Peek RM Jr., Tummuru MK, Blaser MJ, Cover TL: Mosaicism in vacuolating cytotoxin alleles of Helicobacter pylori. Association of specific vacA types with cytotoxin production and peptic ulceration. I Biol Chem 1995, 270(30): |777|- 17777.

10. Censini S, Lange C, Xiang Z, Crabtree JE, Ghiara P, Borodovsky M, Rappuoli R, Covacci A: cag, a pathogenicity island of Helicobacter pylori, encodes type I-specific and disease-associated virulence factors. Proc Natl Acad Sci $U$ S A 1996, 93(25): | 4648-|4653.

I I. Foxall PA, Hu LT, Mobley HL: Use of polymerase chain reactionamplified Helicobacter pylori urease structural genes for differentiation of isolates. Journal of Clinical Microbiology 1992 30(3):739-74I.

12. Oudbier JH, Langenberg W, Rauws EA, Bruin-Mosch C: Genotypical variation of Campylobacter pylori from gastric mucosa. Journal of Clinical Microbiology 1990, 28(3):559-565.

13. Salama N, Guillemin K, McDaniel TK, Sherlock G, Tompkins L, Falkow S: A whole-genome microarray reveals genetic diversity among Helicobacter pylori strains. Proc Natl Acad Sci U S A 2000, 97(26): | 4668-|4673.

14. Simor AE, Shames B, Drumm B, Sherman P, Low DE, Penner JL: Typing of Campylobacter pylori by bacterial DNA restriction endonuclease analysis and determination of plasmid profile. Journal of Clinical Microbiology 1990, 28(I):83-86.

15. Cao P, Cover TL: Two different families of hopQ alleles in Helicobacter pylori. J Clin Microbiol 2002, 40( I 2):4504-45 I I

16. Tomasini ML, Zanussi S, Sozzi M, Tedeschi R, Basaglia G, De Paoli P: Heterogeneity of cag genotypes in Helicobacter pylori isolates from human biopsy specimens. J Clin Microbiol 2003 , 4 I (3):976-980.

17. Colbeck JC, Hansen LM, Fong JM, Solnick JV: Genotypic profile of the outer membrane proteins BabA and BabB in clinical isolates of Helicobacter pylori. Infect Immun 2006, 74(7):4375-4378.

18. Hennig EE, Allen JM, Cover TL: Multiple chromosomal loci for the babA gene in Helicobacter pylori. Infect Immun 2006, 74(5):3046-305I.

19. Figueiredo C, Quint WG, Sanna R, Sablon E, Donahue JP, Xu Q, Miller GG, Peek RM Jr., Blaser MJ, van Doorn LJ: Genetic organization and heterogeneity of the iceA locus of Helicobacter pylori. Gene 2000, 246(1-2):59-68.

20. Go MF, Kapur V, Graham DY, Musser JM: Population genetic analysis of Helicobacter pylori by multilocus enzyme electrophoresis: extensive allelic diversity and recombinational population structure. Journal of Bacteriology 1996, I 78( I 3):3934-3938.

21. Logan RP, Berg DE: Genetic diversity of Helicobacter pylori.[erratum appears in Lancet 1997 Jan 4;349(9044):64]. Lancet 1996, 348(9040): |462-|463.

22. Phadnis SH, llver D, Janzon L, Normark S, Westblom TU: Pathological significance and molecular characterization of the vacuolating toxin gene of Helicobacter pylori. Infection \& Immunity 1994, 62(5): I557-I565.

23. Salaun L, Audibert C, Le Lay G, Burucoa C, Fauchere JL, Picard B: Panmictic structure of Helicobacter pylori demonstrated by the comparative study of six genetic markers. FEMS Microbiol Lett 1998, I 6 I(2):23 I-239.

24. Perales G, Sanchez J, Mohar A, Lara-Lemus R, Hernandez A, HerreraGoepfert R, Barrios-Jacobo I, Ayala G: Single-step PCR amplification and enzyme restriction analysis of the entire Helicobacter pylori cytotoxin vacA gene for genetic variability studies. FEMS Microbiology Letters 1999, I 78(I):55-62.

25. Cover TL: The vacuolating cytotoxin of Helicobacter pylori. Mol Microbiol 1996, 20(2):24I-246.

26. Beji A, Vincent P, Darchis I, Husson MO, Cortot A, Leclerc H: Evidence of gastritis with several Helicobacter pylori strains. Lancet 1989, 2(8676): | 402-| 403

27. Kuipers EJ, Israel DA, Kusters JG, Gerrits MM, Weel J, van Der Ende A, van Der Hulst RW, Wirth HP, Hook-Nikanne J, Thompson SA, Blaser MJ: Quasispecies development of Helicobacter pylori observed in paired isolates obtained years apart from the same host. J Infect Dis 2000, I 8 I (I):273-282.

28. Israel DA, Salama N, Krishna U, Rieger UM, Atherton JC, Falkow S, Peek RM Jr.: Helicobacter pylori genetic diversity within the gastric niche of a single human host. Proc Natl Acad Sci U S A 2001, 98(25): |4625-|4630.

29. McGee DJ, Mobley HL: Mechanisms of Helicobacter pylori infection: bacterial factors. Curr Top Microbiol Immunol 1999 , 24I: | $55-180$

30. Marshall BJ, Barrett LJ, Prakash C, McCallum RW, Guerrant RL: Urea protects Helicobacter (Campylobacter) pylori from the bactericidal effect of acid. Gastroenterology 1990, 99(3):697-702.

31. Mobley HL: The role of Helicobacter pylori urease in the pathogenesis of gastritis and peptic ulceration. Alimentary Pharmacology \& Therapeutics 1996, 10 Suppl I:57-64.

32. Eaton KA, Brooks CL, Morgan DR, Krakowka S: Essential role of urease in pathogenesis of gastritis induced by Helicobacter pylori in gnotobiotic piglets. Infect Immun 1991, 59(7):2470-2475.

33. Eaton KA, Krakowka S: Effect of gastric pH on urease-dependent colonization of gnotobiotic piglets by Helicobacter pylori. Infect Immun 1994, 62(9):3604-3607.

34. Akada JK, Shirai M, Takeuchi H, Tsuda M, Nakazawa T: Identification of the urease operon in Helicobacter pylori and its control by mRNA decay in response to pH. Mol Microbiol 2000 , 36(5): $107 \mid-1084$

35. McGee DJ, Radcliff FJ, Mendz GL, Ferrero RL, Mobley HL: Helicobacter pylori rocF is required for arginase activity and acid protection in vitro but is not essential for colonization of mice or for urease activity. J Bacteriol |999, I 8 I (23):73 |4-7322.

36. Mendz GL, Hazell SL: The urea cycle of Helicobacter pylori. Microbiology 1996, I42 ( Pt 10):2959-2967.

37. Mendz GL, Holmes EM, Ferrero RL: In situ characterization of Helicobacter pylori arginase. Biochim Biophys Acta 1998, I 388(2):465-477

38. Mendz GL, Hazell SL: Aminoacid utilization by Helicobacter pylori. Int J Biochem Cell Biol 1995, 27(1 0): I085-1093.

39. Gobert AP, McGee DJ, Akhtar M, Mendz GL, Newton JC, Cheng Y Mobley HL, Wilson KT: Helicobacter pylori arginase inhibits nitric oxide production by eukaryotic cells: a strategy for bacterial survival. Proc Natl Acad Sci U S A 200I, 98(24): I 3844- I 3849

40. Zabaleta J, McGee DJ, Zea AH, Hernandez CP, Rodriguez PC, Sierra RA, Correa $P$, Ochoa AC: Helicobacter pylori arginase inhibits $T$ cell proliferation and reduces the expression of the TCR zchain (CD3z). J Immunol 2004, I 73(I):586-593.

4I. Dunn BE, Campbell GP, Perez-Perez GI, Blaser MJ: Purification and characterization of urease from Helicobacter pylori. Journal of Biological Chemistry 1990, 265( I 6):9464-9469. 
42. Ferrero RL, Hazell SL, Lee A: The urease enzymes of Campylobacter pylori and a related bacterium. Journal of Medical Microbiology 1988, 27(I):33-40.

43. McGee DJ, Zabaleta J, Viator RJ, Testerman TL, Ochoa AC, Mendz GL: Purification and characterization of Helicobacter pylori arginase, RocF: unique features among the arginase superfamily. Eur J Biochem 2004, 27 I ( I 0): I 952-1962.

44. Langford ML, Zabaleta J, Ochoa AC, Testerman TL, McGee DJ: In Vitro and In Vivo Complementation of the Helicobacter pylori Arginase Mutant Using an Intergenic Chromosomal Site. Helicobacter 2006, I I (5):477-493.

45. Oh JD, Kling-Backhed $H$, Giannakis $M, X u$ J. Fulton RS, Fulton LA, Cordum HS, Wang C, Elliott G, Edwards J, Mardis ER, Engstrand LG, Gordon Jl: The complete genome sequence of a chronic atrophic gastritis Helicobacter pylori strain: evolution during disease progression. Proc Natl Acad Sci U S A 2006, 103(26):9999-10004.

46. Eppinger M, Baar C, Linz B, Raddatz G, Lanz C, Keller H, Morelli G, Gressmann H, Achtman M, Schuster SC: Who ate whom? Adaptive Helicobacter genomic changes that accompanied a host jump from early humans to large felines. PLoS Genet 2006, 2(7): el 20.

47. Reynolds DJ, Penn CW: Characteristics of Helicobacter pylori growth in a defined medium and determination of its amino acid requirements. Microbiology 1994, I 40 ( Pt 10):2649-2656.

48. Testerman TL, Conn PB, Mobley HL, McGee DJ: Nutritional requirements and antibiotic resistance patterns of Helicobacter species in chemically defined media. J Clin Microbiol 2006, 44(5): $1650-1658$.

49. Testerman TL, McGee DJ, Mobley HL: Helicobacter pylori growth and urease detection in the chemically defined medium Ham's F-I 2 nutrient mixture. J Clin Microbiol 200I, 39(II):3842-3850.

50. Suerbaum S, Smith JM, Bapumia K, Morelli G, Smith NH, Kunstmann E, Dyrek I, Achtman M: Free recombination within Helicobacter pylori. Proc Natl Acad Sci U S A 1998, 95(2I): I 26I 9-I 2624

5I. Tomb JF, White O, Kerlavage AR, Clayton RA, Sutton GG, Fleischmann RD, Ketchum KA, Klenk HP, Gill S, Dougherty BA, Nelson K, Quackenbush J, Zhou L, Kirkness EF, Peterson S, Loftus B, Richard son D, Dodson R, Khalak HG, Glodek A, McKenney K, Fitzegerald LM, Lee N, Adams MD, Hickey EK, Berg DE, Gocayne JD, Utterback TR, Peterson JD, Kelley JM, Cotton MD, Weidman JM, Fujii C, Bowman C, Watthey L, Wallin E, Hayes WS, Borodovsky M, Karp PD, Smith HO, Fraser CM, Venter JC: The complete genome sequence of the gastric pathogen Helicobacter pylori. Nature 1997, 388(6642):539-547.

52. Hennig EE, Mernaugh R, Edl J, Cao P, Cover TL: Heterogeneity among Helicobacter pylori strains in expression of the outer membrane protein BabA. Infect Immun 2004, 72(6):3429-3435.

53. Naito M, Yamazaki T, Tsutsumi R, Higashi H, Onoe K, Yamazaki S, Azuma T, Hatakeyama M: Influence of EPIYA-repeat polymorphism on the phosphorylation-dependent biological activity of Helicobacter pylori CagA. Gastroenterology 2006, I30(4): I I8I-I I90.

54. van Doorn LJ, Figueiredo C, Sanna R, Blaser MJ, Quint WG: Distinct variants of Helicobacter pylori cagA are associated with vacA subtypes. J Clin Microbiol 1999, 37(7):2306-23II.

55. Pflock M, Finsterer N, Joseph B, Mollenkopf H, Meyer TF, Beier D: Characterization of the ArsRS regulon of Helicobacter pylori, involved in acid adaptation. Journal of Bacteriology 2006, I 88(1 0):3449-3462.

56. Wen Y, Marcus EA, Matrubutham U, Gleeson MA, Scott DR, Sachs G Acid-adaptive genes of Helicobacter pylori. Infect Immun 2003 7I(I0):592I-5939.

57. McGee DJ, Coker C, Testerman TL, Harro JM, Gibson SV, Mobley HL: The Helicobacter pylori flbA flagellar biosynthesis and regulatory gene is required for motility and virulence and modulates urease of $\mathbf{H}$. pylori and Proteus mirabilis. J Med Microbiol 2002, 5 I (I I):958-970.

58. McGee DJ, May CA, Garner RM, Himpsl JM, Mobley HL: Isolation of Helicobacter pylori genes that modulate urease activity. J Bacteriol 1999, I 8 I (8):2477-2484.

59. Sambrook J E. F. Fritsch, and T. Maniatis.: Molecular Cloning: A Laboratory Manual. 2nd edition. Edited by: Laboratory. CSH. Cold Spring Harbor, N. Y.; 1989.
60. National Center for Biotechnology Information [http:// www.ncbi.nlm.nih.gov]

61. ExPASy Proteomics Server [http://us.expasy.org]

62. Thompson JD Higgins, D.G. and Gibson, T.J: CLUSTAL W: improving the sensitivity of progressive multiple sequence alignment through sequence weighting, positions-specific gap penalties and weight matrix choice. Nucleic Acids Research 1994, 22:4673-4680.

63. European Bioinformatics Institute: ClustalW [http:// www.ebi.ac.uk/clustalw/]

64. Thompson JD Gibson,T.J., Plewniak,F., Jeanmougin,F. and Higgins,D.G.: The ClustalX windows interface: flexible strategies for multiple sequence alignment aided by quality analysis tools. Nucleic Acids Research 1997, 24:4876-4882.

65. Rod Page's Home Page [http://taxonomy.zoology.gla.ac.uk/rod/ rod.html]

66. Page RDM: TREEVIEW: An application to display phylogenetic trees on personal computers. Computer Applications in the Biosciences 1996, 1 2:357-358.
Publish with Bio Med Central and every scientist can read your work free of charge

"BioMed Central will be the most significant development for disseminating the results of biomedical research in our lifetime. "

Sir Paul Nurse, Cancer Research UK

Your research papers will be:

- available free of charge to the entire biomedical community

- peer reviewed and published immediately upon acceptance

- cited in PubMed and archived on PubMed Central

- yours - you keep the copyright
BiolMedcentral 